\title{
Effect of bupleurum liver-coursing powder on acute gastric ulcer and expressions of gastric mucosal epidermal growth factor and receptor
}

\author{
Ji Yuan, Zhang Yan, Tao Gen* \\ Department of Pharmacy, Nanjing Qixia District Hospital, Jiangsu Nanjing 210046, People's Republic of China \\ *For correspondence: Email: If1252@163.com
}

Sent for review: 6 July 2018

Revised accepted: 29 August 2018

\begin{abstract}
Purpose: To investigate the ameliorative effect of bupleurum liver-coursing powder on symptoms of acute gastric ulcer (AGU), and on the expressions of gastric mucosal epidermal growth factor (EGF) and EGF receptor (EGFR).

Methods: A total of 120 patients were recruited over a 1-year period for this study, and assigned to observation and control groups (60 patients each). The observation group consisted of 31 males and 29 females aged between 23 and 55 years (mean age, $38.77 \pm 4.36$ years; mean disease history, $7.94 \pm$ 2.49 days). Control group consisted of 33 males and 27 females aged between 26 and 51 years (mean age, $37.68 \pm 4.67$ years; mean disease history, $8.06 \pm 2.31$ days). Following 14 days of treatment, clinical symptoms such as gastric swelling and pain, chest distress, belching, and sour regurgitation were recorded and analyzed. Serum levels of C-reactive protein (CRP), IL- 6 and TNF- $\alpha$ were assayed using ELISA, while the expressions of EGF and EGFR were determined using immuno-histochemical staining.

Results: Total effectiveness (recovery, excellent, effective and ineffective) in observation patients $(91.70 \%)$ was significantly higher $(p<0.001)$ than in control group $(65.0 \%)$. Prior to treatment, both groups were comparable with respect to the major symptoms of AGU, and serum levels of CRP, TNF- $\alpha$ and IL-6. However, there were significant reductions in symptoms and serum levels of CRP, TNF- $\alpha$ and IL-6 in bupleurum liver-coursing powder-treated patients, post-treatment $(p<0.05)$. Similarly, after treatment, there were significant increases in the expressions of EGF and EGFR in the observation patients, relative to control patients $(p<0.05)$.

Conclusion: Bupleurum liver-coursing powder is effective in ameliorating symptoms of AGU, and it enhances the expressions of EGF and EGFR.
\end{abstract}

Keywords: Acute gastric ulcer, Bupleurum liver-coursing powder, Inflammation-related factors, Epithelial growth factor, Receptor

This is an Open Access article that uses a funding model which does not charge readers or their institutions for access and distributed under the terms of the Creative Commons Attribution License (http://creativecommons.org/licenses/by/4.0) and the Budapest Open Access Initiative (http://www.budapestopenaccessinitiative.org/read), which permit unrestricted use, distribution, and reproduction in any medium, provided the original work is properly credited.

Tropical Journal of Pharmaceutical Research is indexed by Science Citation Index (SciSearch), Scopus, International Pharmaceutical Abstract, Chemical Abstracts, Embase, Index Copernicus, EBSCO, African Index Medicus, JournalSeek, Journal Citation Reports/Science Edition, Directory of Open Access Journals (DOAJ), African Journal Online, Bioline International, Open-J-Gate and Pharmacy Abstracts

\section{INTRODUCTION}

Gastric ulcer is a disease of the digestive system characterized by late onset and quick relapse. There are controversies surrounding its pathogenesis. Some researchers have speculated that it may be closely related to the attack and protective factors in the gastric mucosa [1]. Acute gastric ulcer (AGU) is characterized by complications such as massive 
hemorrhage and perforation. Some of the causes of AGU include physical and mechanical injuries, chemical burns, and stress; and its current treatment strategy is ineffective $[2,3]$. According to Traditional Chinese Medicine (TCM), AGU is categorized as "gastric pain", "costalgia", pi syndrome, dirty diet injury of the stomach and spleen; liver depression and qi stagnation. In AGU, there is usually a functional disharmony between the liver and stomach, and the treatment option is soothing the liver, strengthening the spleen and activating blood circulation [4-6]. The aim of this study was to investigate the ameliorative effect of bupleurum liver-coursing powder on the symptoms of AGU, and the expressions of gastric mucosal EPG factor and EPGR.

\section{EXPERIMENTAL}

\section{Materials}

Omeprazole and clarithromycin were purchased from Yunnan Yong-An Pharmaceutical Co., Ltd.; Amoxicillin was obtained from Shandong Lukang Drugs Group Ltd., and CRP, TNF- $\alpha$ and IL-6 ELISA kits were products of Diagnostic Systems $\mathrm{GmbH}$ (Shanghai). Immuno-histochemical staining (SP) kits were purchased from Wuhan Boster Biotechnology Engineering Co., Ltd.

Approval for this study was given by the committee on ethics of the Department of Pharmacy, Nanjing Qixia District Hospital, Jiangsu Nanjing, China (approval no. 1802), and was carried out in compliance with the Helsinki Declaration as amended in 1996 [7].

\section{Patients and clinical data}

A total of 120 patients were recruited over a 1year period for this study, and they comprised observation patients and control patients (60 patients each). The observation group consisted of 31 males and 29 females aged between 23 and 55 years (mean age $=38.77 \pm 4.36$ years; mean disease history $=7.94 \pm 2.49$ days). The control group consisted of 33 males and 27 females aged between 26 and 51 years (mean age $=37.68 \pm 4.67$ years; mean disease history $=8.06 \pm 2.31$ days). Patients in the observation group were all single gastric ulcer and first-onset cases. The inclusion criteria were: (1) patients who saw a doctor less than one month from the time of onset; (2) patients whose conditions were characterized by liver-stomach disharmony syndrome; (3) patients aged between 18 and 60 years; and (4) patients who signed written informed consent with their family members. Patients whose time of onset occurred twice within 6 months, with duodenal ulcer, liver-kidney dysfunction, stress or chronic gastric ulcer, bleeding, perforation and canceration, were excluded. There were no significant differences in the general clinical data of the patients.

\section{Treatment protocol}

Patients in the control group received routine treatment, omeprazole (20 $\mathrm{mg} /$ granule $)$, clarithromycin $(500 \mathrm{mg} / \mathrm{kg})$, and amoxicillin (1000 $\mathrm{mg} / \mathrm{kg}$ ) twice daily consecutively for 14 days. Patients in the observation group received bupleurum liver-coursing powder and the treatment method in the control group. The bupleurum liver-coursing powder consisted of 15 $\mathrm{g}$ of bupleurum, $15 \mathrm{~g}$ of citrus, $10 \mathrm{~g}$ of white peony root, $10 \mathrm{~g}$ of Fructus aurantii, $10 \mathrm{~g}$ of Rhizoma chuanxiong, $10 \mathrm{~g}$ Rhizoma cyperi and $10 \mathrm{~g}$ Radix liquiritiae, all dissolved in $400 \mathrm{~mL}$ of distilled water. A single dose of the solution was administered orally twice daily (morning and evening) consecutively for two weeks.

\section{Criteria for determination of effectiveness}

Clinical effectiveness was categorized as follows: (a) Recovery: $\geq 90 \%$ decrease in symptoms; disappearance of ulcer, improvement in signs and symptoms, but with some manifestations of inflammation; (b) Excellent: 70 to $89 \%$ decrease in symptoms; $\geq 50 \%$, shrinkage of ulcer and an improvement in signs and symptoms; (c) Effective: symptoms decreased from 30 to $69 \%$; $<50 \%$ shrinkage of ulcer and (d) Ineffective: < $30 \%$ decrease in symptom. The total effectiveness was calculated as in Eq 1.

$T(\%)=\{(r+e 1+e 2) / n\} 100$

where $T$ is total effectiveness, $r$ is recovery, $e 1$ is excellent, $e 2$ is effective.

\section{Determination of serum levels of CRP, TNF- $\alpha$ and IL-6}

Fasting venous blood ( $3 \mathrm{~mL}$ ) was taken from the patients before and after treatment, and centrifuged at $3000 \mathrm{rpm}$ for $10 \mathrm{~min}$ to obtain serum samples which were stored at $-80^{\circ} \mathrm{C}$ prior to analysis. Serum levels of CRP, TNF- $\alpha$ and IL6 were determined using ELISA kits. Portions of gastric tissue within the margin of ulcer were collected, fixed in paraformaldehyde (40\%) for $16 \mathrm{~h}$, dehydrated, embedded in paraffin, and sectioned into 5- $\mu \mathrm{m}$ slices using a microtome. The expressions of EGF and EGFR on the gastric mucosa were determined using immunohistochemical staining (SP method). 


\section{Observation indices}

Gastrectasia and gastric oppression, pain in the ribs, fullness of the chest, belching, and sour regurgitation were scored according to the Clinical Study Guide Principle of New Traditional Chinese Medicine. The higher the score, the more severe the clinical symptom.

\section{Statistical analysis}

Data were subjected to statistical analysis using SPSS (22.0), while $x 2$ test was used for the count data. Values of $p<0.05$ were considered statistically significant.

\section{RESULTS}

\section{Clinical effectiveness of therapy}

Table 1 shows that total effectiveness was higher in the observation patients $(91.70 \% ; p<0.001)$ than in control group (65.00\%).

\section{Symptoms of patients before and after treatment}

Prior to treatment, there were no significance differences $(p>0.05)$ in the major symptoms of AGU (gastric swelling and pain, chest distress, belching, and sour regurgitation) between patients in the observation and control groups. However, significant reductions in these symptoms were seen post-treatment $(p<0.05)$ in the observation group, when compared to the control group (Table 2).

\section{Inflammation-related factors before and after treatment}

Serum levels of CRP, TNF- $\alpha$ and IL- 6 between the two groups before treatment were comparable. However, after treatment, their serum levels in the patients treated with bupleurum liver-coursing powder were significantly lower than those of the control group $((p<0.05$; Table 3$)$.

\section{Effect of treatment on expressions of EGF and EGFR}

As depicted in Table 4, the expressions of EGF and EGFR in the patients treated with bupleurum liver-coursing powder were increased significantly post-treatment, when compared to the control group $(p<0.05)$.

\section{DISCUSSION}

Tissue integrity and function are disrupted in patients with AGU, with evidence of connective tissue filling, narrowing of mucous layer, disorders in gland and microvascular structures as well hemorrhage and perforation, thereby severely affecting prognosis $[8,9]$. In TCM, it is

Table 1: Clinical effectiveness of treatments

\begin{tabular}{lcccccc}
\hline Group & $\mathbf{n}$ & Recovery & Excellent & Effective & Ineffective & Total effectiveness \\
\hline Control & 60 & $6(10.00)$ & $17(28.33)$ & $16(26.67)$ & $21(35.00)$ & $39(65.00)$ \\
Observation & 60 & $13(21.67)$ & $26(43.33)$ & $16(26.67)$ & $5(8.33)$ & $55(91.69)$ \\
$X^{2}$ & & & & & & 12.570 \\
$p$ & & & & & 0.001 \\
\hline Values are $\mathrm{n}(\%)$ & & & &
\end{tabular}

Table 2: Symptoms in patients before and after treatment $(n=60)$

\begin{tabular}{|c|c|c|c|c|c|c|c|}
\hline Group & $\mathbf{n}$ & & $\begin{array}{l}\text { Gastric swelling } \\
\text { and oppression }\end{array}$ & $\begin{array}{l}\text { Gastric pain } \\
\text { in the ribs }\end{array}$ & $\begin{array}{l}\text { Chest } \\
\text { fullness }\end{array}$ & Belching & $\begin{array}{l}\text { Sour } \\
\text { regurgitation }\end{array}$ \\
\hline \multirow[t]{2}{*}{ Control } & 60 & Before treatment & $3.66 \pm 0.28$ & $2.31 \pm 0.36$ & $2.71 \pm 0.42$ & $2.19 \pm 0.39$ & $2.57 \pm 0.46$ \\
\hline & & After treatment & $1.18 \pm 0.31$ & $1.47 \pm 0.31$ & $1.69 \pm 0.38$ & $1.36 \pm 0.41$ & $1.61 \pm 0.36$ \\
\hline \multirow[t]{2}{*}{ Observation } & & Before treatment & $3.61 \pm 0.38$ & $2.40 \pm 0.42$ & $2.63 \pm 0.37$ & $2.23 \pm 0.44$ & $2.64 \pm 0.40$ \\
\hline & 60 & After treatment & $1.03 \pm 0.24$ & $1.01 \pm 0.26$ & $1.16 \pm 0.34$ & $0.63 \pm 0.28$ & $0.91 \pm 0.31$ \\
\hline
\end{tabular}

${ }^{\star} P<0.05$ compared to control

Table 3: Inflammation-related factors before and after treatment

\begin{tabular}{lclccc}
\hline Group & $\mathbf{n}$ & Time & CRP $(\mathbf{m g} / \mathbf{m L})$ & TNF- $\mathbf{\alpha}(\boldsymbol{\mu g} / \mathbf{m L})$ & IL- $\mathbf{6}(\mathbf{p g} / \mathbf{m L})$ \\
\hline Control & 60 & Before treatment & $16.73 \pm 3.36$ & $20.45 \pm 5.06$ & $113.77 \pm 13.85$ \\
& & After treatment & $13.95 \pm 3.66$ & $15.33 \pm 4.61$ & $78.49 \pm 11.83$ \\
Observation & 60 & Before treatment & $16.56 \pm 3.42$ & $20.19 \pm 5.39$ & $115.02 \pm 12.88$ \\
& & After treatment & $9.07 \pm 3.14^{*}$ & $11.28 \pm 3.61^{*}$ & $71.66 \pm 10.49^{*}$ \\
\hline
\end{tabular}

${ }^{\star} P<0.05$ compared to control 
Table 4: Expressions of EGF and EGFR before and after treatment

\begin{tabular}{|c|c|c|c|c|}
\hline \multirow{3}{*}{$\begin{array}{c}\text { Group } \\
\text { Control }\end{array}$} & $\mathbf{n}$ & & EGF (pg/mL) & EGFR (\%) \\
\hline & 60 & Before treatment & $163.27 \pm 25.16$ & $15.47 \pm 3.38$ \\
\hline & & After treatment & $284.50 \pm 34.62$ & $24.47 \pm 4.13$ \\
\hline Observation & 60 & $\begin{array}{l}\text { Before treatment } \\
\text { After treatment }\end{array}$ & $\begin{array}{c}165.71 \pm 25.01 \\
437.49 \pm 41.53^{*}\end{array}$ & $\begin{array}{c}15.59 \pm 3.42 \\
29.39 \pm 3.87^{*}\end{array}$ \\
\hline
\end{tabular}

${ }^{*} p<0.05$ compared with control

believed that AGU is related to deficiency of healthy qi and stagnation of spleen and stomach. Liver-anger invading the lungs, dirty diet and stagnation of damp-heat are believed to cause the unsmoothing of qi and blood, injury of gastric mucosa, and growth defects in gastric mucosa. The spleen is the origin of qi and blood, and has a close functional relationship with the liver and stomach. Deficiency in the functions of spleen causes deficiency of qi and blood transformation, lack of proper stomach nutrition, and stagnation of blood stasis, which are some of the key factors responsible for AGU relapse. Soothing the liver, strengthening the spleen and activating blood flow constitute the treatment options for AGU in TCM [10-12].

In the present study, total effectiveness in the observation group was significantly higher than that of control. This result suggests that bupleurum liver-coursing powder may be effective in the treatment of AGU caused by a functional disharmony between the liver and stomach, and that this powder exerts its effect probably by regulating spleen and stomach functions [13]. Symptoms such as gastric swelling, pain in the ribs, chest distress, belching and sour regurgitation decreased markedly in patients treated with the bupleurum liver-coursing powder, suggesting that this liver-coursing powder may lower or alleviate the clinical symptoms of AGU.

The herbs that constitute bupleurum livercoursing powder have been shown to exert effects such as soothing of liver, strengthening of spleen and activation of blood flow, which can lower the clinical symptoms of AGU [14]. For instance, white peony root can nourish and retain yin, and stabilize the stomach thereby stopping pain, while Fructus aurantil may purge the spleen and its stagnation, and regulate spleen transformation and transportation of metabolites, thereby strengthening the soothing functions of liver and qi, and relieving depression. A combination of white peony root with Radix glycyrrhizae may relieve and stop emergency pain associated with AGU. Rhizoma Chuanxiong can promote qi, reduce depression, and activate blood flow, while Rhizoma cyperi may regulate $q i$, stabilize the stomach and stop pain.
In this study, the serum levels of CRP, TNF- $\alpha$ and IL- 6 were markedly reduced in the patients treated with bupleurum liver-coursing powder. Studies have shown that bupleurum and Corydalis yanhuosuo can ease pain, improve microcirculation, and accelerate mucosal repair [15]. The recovery process of ulcer is complicated and regulated by several factors, and it is closely related to the EGF of gastric mucosa and its receptor (EGFR) [16]. The expressions of EGF and EGFR were significantly elevated in the bupleurum liver-coursing powdertreated patients. The EGF can inhibit the secretion of gastric acid, increase the volume of blood perfusing the gastric mucosa, and enhance the proliferation of gastric mucosal cells and synthesis of hyaluronidase of epithelial cells. Thus, EGF promotes the recovery of AGU patients. The synergistic effect of EGF and EGFR can promote recovery of gastric mucosa, and reduce the secretion of gastric acid by increasing synthesis of DNA and protein $[17,18]$.

\section{CONCLUSION}

Bupleurum liver-coursing powder is effective in ameliorating the symptoms of AGU via enhancement of the expressions of EGF and EGFR. Thus, bupleurum liver-coursing powder is a potentially effective treatment strategy for AGU.

\section{DECLARATIONS}

\section{Acknowledgement}

This work was supported with grants from the National Science Foundation of China (NSFC) (no. 81404790).

\section{Conflict of interest}

No conflict of interest is associated with this work.

\section{Contribution of authors}

We declare that this work was done by the author(s) named in this article and all liabilities pertaining to claims relating to the content of this article will be borne by the authors. All authors read and approved the manuscript for 
publication. Taogen conceived and designed the study, Jiyuan, Zhangyan, Taogen collected and analysed the data, while Jiyuan wrote the manuscript.

\section{REFERENCES}

1. Wu JZ, Liu YH, Liang JL. Protective role of $\beta$-patchoulene from pogostemon cablin against indomethacin-induced gastric ulcer in rats: involvement of anti-inflammation and angiogenesis. Phytomed 2018; 39(2): 111-118.

2. Li J, Wang T, Zhu Z. Structural features and anti-gastric ulcer effects of inulin-type fructan CP-A from the roots of codonopsis pilosula (Franch). Mol 2017; 22(12): 2258.

3. Libânio $D$, Brandão $C$, Pimentel-Nunes $P$, Dinis-Ribeiro M. Perforated gastric ulcer associated with antiangiogenic therapy. GE Port J Gastroenterol 2017; 24(6): 285-287.

4. Han XF. Effects of supplementing qi and nourishing yin prescription on serum inflammatory factors, behavioristics and EGF expression of acute gastric model rats. J Emerg Tradit Chin Med 2017; 26(9): 15961598.

5. Zhang $\mathrm{H}$. Clinical observation of integrated traditional Chinese and western medicine in treatment of refractory peptic ulcer. Hebei J Tradit Chin Med 2018; 40(2): 3334.

6. Man GL, Shi FZ. The research of Yiqi huoxue decoction on healing quality of gastric mucosa in rats with acute gastric ulcer. J Emerg Tradit Chin Med 2015; 24(11): 1939-1941.

7. World Health Organization. Declaration of Helsinki. Br Med J 1996; 313(7070): 1448-1449.

8. Chen $Q M$, Jiang $Y N$, Huang $L H$. Clinical effects observation of treating acute gastric ulcer bleeding under endoscopy. Chin J Mod Drug Appl 2016; 10(3): 69-70.

9. Wang SG, Yu HL, Ma M. Effect of omeprazole, amoxicillin and metronidazole on serum levels of inflammatory cytokines and gastric gastrin family indexes of patients with gastric ulcer of Hp infection. Chin J Nosocomiol 2016; 26(11): 2470-2472.

10. Wang LJ. Effects of adjusted zuojin pills with triple therapy on serum inflammatory factors of gastric ulcer patients. Med Inf 2016; 29(13): 253-253.

11. Su FZ, Yu WT, Yang MX. Influence of Weiyanyin formula on the expression of epidermal growth factor and transforming growth factor- $\beta 1$ in gastric ulcer rats. $J$ Tradit Chin Med 2015; 56(5): 418-422.

12. Hou $L Q$, Jin $Z X$, Chen J. Effect of Shugan Jieyu capsules on improving symptoms of chronic gastritis patients with depression and improving the situation of depression. Acta Chin Med Pharmacol 2015; 43(3): 108-110.

13. Ni $X Q$, Cao MQ, Wu ZZ, Li LM. Research progress of chemical component and pharmacologic action of Bupleurum Liver-Coursing Powder. Shanghai J TCM 2017; 51(9): 109-113.

14. Deng WJ, Peng CC, Pan XM. Clinical observation on modified bupleurum liver-coursing powder in treating gastric ulcer with positive HP of disharmony between liver and stomach. J North Pharm 2016; 13(5): 49-50.

15. Zhao $Y, L i Y X$, Lin $Q$. Effect of chaihushugansan combined with fluoxetine on IL-6, IL-1 $\beta, T N F-\alpha$ in postpartum depression. Chin J Biochem Pharm 2016; 36(4): 127-129.

16. Ge GP, Yang $F$, Zhou GX. The effect of chuyouyuyangmianjian granule on the VEGF of gastric ulcer in rats induced by acetic acid. World Chin Med 2016; 11(4): 695-698.

17. Luo JC, Peng YL, Chen TS. Clopidogrel inhibits angiogenesis of gastric ulcer healing via downregulation of vascular endothelial growth factor receptor 2. J Formos Med Assoc 2016; 115(9): 764-772.

18. Zheng $P$, Niu FL, Liu WZ, Shi Y, Lu LG. Antiinflammatory mechanism of oxymatrine in dextran sulfate sodium-induced colitis of rats. World $J$ Gastroenterol 2005; 11(31): 4912-4915. 